\title{
A gestão da inovação na educação a distância
}

\section{Innovation management in distance education}

\author{
Elenise Maria de Araújo ${ }^{1}$ \\ José Dutra de Oliveira Neto ${ }^{1}$ \\ Edson Walmir Cazarini ${ }^{1}$ \\ Selma Regina Martins Oliveira²
}

\begin{abstract}
Resumo: A reflexão sobre o processo de inovação no setor educacional envolve uma série de componentes que, da perspectiva da Engenharia de Produção, são sistematizados e possibilitam um considerável lucro e valor para as instituições. A sedimentação deste processo no planejamento estratégico e no modelo de negócio da instituição depende da postura dos gestores e da equipe de profissionais, que devem promover a quebra de paradigmas e a constituição de um novo modelo de negócio para a Educação a Distância (EAD). Descrevem-se, neste trabalho, alguns pontos fundamentais para a análise da inovação em EAD que envolve os subsistemas e componentes do planejamento estratégico, tais como: as fontes de conhecimento; a criação; a transmissão; a interação; o aluno; e o ambiente de aprendizagem. A inclusão da gestão da inovação nas instituições educacionais prevê a prospecção de algumas regras para a adequação do modelo de negócio, incentivado e balizado nos indicativos de proposição de valor, cadeia de suprimentos e nas características do cliente-alvo que garantem o sucesso de todo o processo. Além desses parâmetros de adequação, é necessário atingir um alto nível de envolvimento dos gestores e da equipe de docentes e técnicos para a implementação da inovação na organização. No Brasil, espera-se que os especialistas e as políticas públicas contemplem, em seus modelos de EAD, projetos de inovação com alto grau de flexibilidade e criatividade, que permitam a integração de saberes, a capacitação de equipes multidisciplinares e o uso racional de tecnologias de informação e comunicação para o compartilhamento igualitário do conhecimento.
\end{abstract}

Palavras-chave: Inovação em EAD. Planejamento estratégico. Modelo de negócio.

\begin{abstract}
The process of innovation in the education sector involves a series of elements, which, from the Production Engineering perspective, can be systematized and can generate substantial profit and value in educational institutions. Successful strategic planning process and business model depend on the managers and team of professionals' approaches to break paradigms and develop a new distance education business model. This study describes some fundamental aspects of innovation in distance education analysis, which involve the subsystems and elements of strategic planning such as the knowledge source, creation, transmission, and interaction; the learner; and the learning environment. Incorporating innovation management in educational institutions requires some rules to adjust the business model motivated and driven by value proposition indicators, supply chain, and the target customer characteristics that ensure the success of the process. In addition to these adequacy parameters, deep involvement by managers, educators, and technicians is necessary to support innovation implementation. In Brazil, it is expected that professionals and public policies consider including distance education in their innovation model projects with high degree of flexibility and creativity to enable integration of knowledge, proper training of multidisciplinary teams, and the rational use of information technology and communication for equal sharing of knowledge.
\end{abstract}

Keywords: Innovation in distance education. Strategic planning. Business model.

\section{Introdução}

As instituições de ensino dispostas a oferecer cursos na modalidade a distância devem reformular a gestão estratégica da própria estrutura organizacional e de

seus processos técnicos e administrativos. Diante desse novo paradigma, todos os atores institucionais são convocados a participar ativamente do processo de

\footnotetext{
${ }^{1}$ Departamento de Engenharia de Produção, Escola de Engenharia de São Carlos - EESC, Universidade de São Paulo - USP, Av. Trabalhador São-carlense, 400, CEP 13566-590, São Carlos, SP, Brasil, e-mail: elenisea@ sc.usp.br; dutra@usp.br; cazarini@sc.usp.br

${ }^{2}$ Universidade Federal do Tocantins - UFT, Av. NS 15, AlC 14, s/n, Centro, CEP 77020-210, Palmas, TO, Brasil,

e-mail: selmaregina@webmail.uft.edu.br
}

Recebido em 6/6/2011 — Aceito em 26/10/2012

Suporte financeiro: Nenhum. 
idealização, planejamento, execução e sustentabilidade do curso a distância, refletindo sobre os vários aspectos que permeiam o próprio planejamento estratégico do ensino, a utilização das ferramentas tecnológicas e a gestão estratégica da inovação.

Para esse novo modelo de negócio, as instituições educacionais podem criar inúmeros valores que atendam os alunos e seus diferentes estilos de aprendizagem, background e características socioculturais.

No entanto, é essencial destacar a importância das estratégias de inovação no processo de planejamento estratégico de cursos em EAD, das instituções educacionais, que executam a implementação e a avaliação sistemática de produtos e serviços oferecidos, balizando suas ações em regras, escalas ou níveis de inovação.

A partir dessa análise serão identificados os inúmeros fatores que interferem no processo de planejamento e execução do plano didático-pedagógico de um curso em EAD e as relações existentes entre as variáveis de inovação, modelo de transmissão e acesso ao conhecimento, que, durante séculos, se dão da mesma maneira.

O desenvolvimento exponencial das tecnologias da comunicação e informação, que já estão incorporadas ao cotidiano dos indivíduos, exigem seu espaço no processo educacional. Dessa forma, para incorporar a inovação na EAD é necessário construir modelos criativos e flexíveis que valorizem os produtos e serviços oferecidos, atentando para a qualidade e para a satisfação do cliente-alvo, ou seja, do aluno.

Este artigo propõe a reflexão sobre alguns fatores potenciais de inovação que a EAD online representa no planejamento estratégico de instituições educacionais e ressalta ainda outros indicadores de qualidade para cursos online que sustentam uma prática eficaz e eficiente da gestão estratégica da inovação.

\section{Planejamento estratégico da EAD}

Levy (2003) afirma que o sucesso de um curso em EAD depende da reavaliação por parte dos administradores, funcionários, corpo docente e dos alunos dos programas oferecidos. Aponta ainda várias áreas específicas que são levadas em consideração no planejamento e desenvolvimento de cursos a distância online, entre elas, destacam-se: a visão e os planos; o currículo; a formação e suporte; os serviços aos estudantes; o treinamento de estudantes; e apoio. Sobre a missão e visão da instituição, Levy (2003) considera essencial que os gestores, docentes e técnicos administrativos e operacionais envolvidos na implementação da EAD, passem a entender e aceitar a declaração da visão da instituição e se mostrem dispostos a assumir as suas implicações e colaborar no processo de mudança, que envolve os aspectos físicos, tecnológicos, organizacionais, culturais e programáticos da instituição. Dessa forma, a fase de planejamento e o desenvolvimento de políticas institucionais para cursos online são a chave para um programa de aprendizagem eficiente, pois permitirá, entre outros benefícios, a racionalização de investimentos financeiros e do tempo para desenvolvimento de programas de capacitação técnica, e da própria qualidade da educação para a comunidade. O sistema operacional de EAD envolve subsistemas que, de forma equilibrada, contribuem para a sustentabilidade do curso, são eles: fontes de conteúdo; criação do programa/curso; transmissão/mídia; interação; aluno; e o ambiente de aprendizagem (Figura 1). Na ótica da gestão da inovação, as instituições educacionais devem definir uma política que envolva harmoniosamente esses subsistemas, garantindo o sucesso do curso online e a satisfação do aluno.

Os conceitos envolvidos simultaneamente no processo de inovação e no planejamento estratégico de cursos na modalidade EAD são descritos a seguir para suscitar reflexões sobre o tema.

a) Fontes de conteúdo: segundo Moore e Kearsley (2008), essas fontes de conhecimento são de responsabilidade da organização que delega aos especialistas a constituição de um conteúdo que abarque teoria, prática, literatura e o uso da tecnologia. O enfoque inovador a ser implementado nesse subsistema é a construção coletiva dessas fontes de conhecimento, que congregue as experiências dos especialistas, corpo docente, tutores e alunos e prepare a formatação de um banco de modelos ou de casos que serão compartilhados entre todos os envolvidos. Para Moore e Kearsley (2008), um dos marcos referenciais para a criação de um curso online com qualidade inclui o próprio desenvolvimento do curso e a definição das regras para constituição das fontes de conhecimento, que envolvem diretrizes para criação, desenvolvimento e veiculação do curso, materiais de instrução, análise, síntese e avaliação dos alunos sobre o programa e o curso. Levy (2003) afirma que o planejamento para cursos em EAD geralmente incide sobre orçamento e capacitação de pessoal e não em questões críticas pedagógicas, no entanto, a infraestrutura de tecnologia e a abordagem para execução de novos métodos de execução e de orientação teórico-pedagógica não devem ser ignoradas. O plano curricular, o design instrucional e o estilo de instrução interferem diretamente sobre o planejamento estratégico para cursos em EAD, pois muitos docentes ainda rejeitam a ideia de mudar a forma de transmitir o conhecimento e continuam apostando em palestras interativas, atividades de grupos, em laboratórios fechados. Outros docentes não adaptaram seus recursos didáticos às novas tecnologias, como os Ambientes Virtuais de Aprendizagem e ferramentas multimídias. Além disso, as instituições mantêm o plano curricular de cursos 


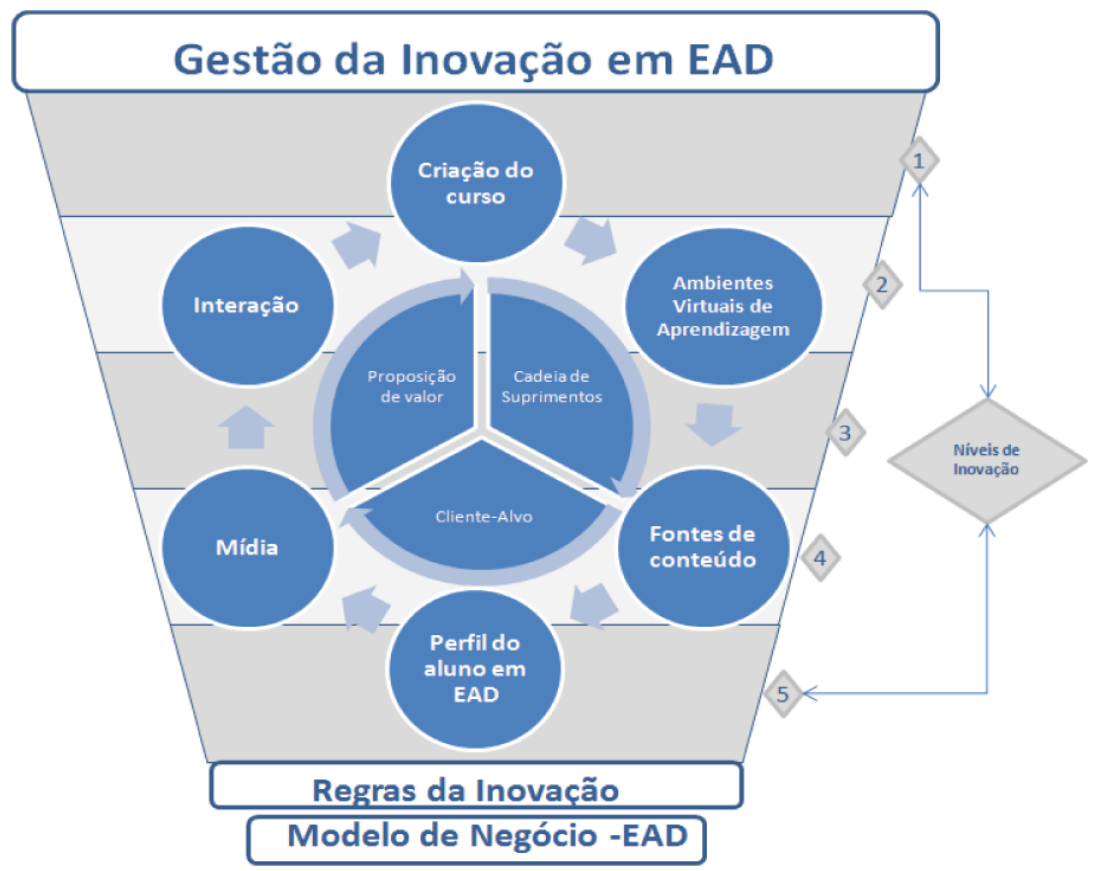

Figura 1. Subsistemas do planejamento estratégico para EAD.

em EAD atrelados aos padrões tradicionais de cursos presenciais, impondo um cronograma rígido e pouco prático para um perfil de aluno totalmente diferente e com necessidades mais específicas se comparados àqueles inscritos em cursos tradicionais.

Segundo Tidd, Bessant e Pavitt (2008), a implementação do processo de inovação e a aquisição eficiente de conhecimento envolvem a combinação do conhecimento novo e o já existente, o tecnológico e o mercadológico, criando conexões nos sistemas de inovação no interior da empresa que deve possuir habilidades para encontrar, selecionar e transferir tecnologia de fora para dentro. Desta forma, a construção e manutenção de um sistema de fontes de conhecimento dependem da rede de relacionamentos, das fontes tecnológicas e do processo de seleção, negociação, implementação e aprendizagem da instituição. As fontes de conteúdo dependem também da realização de parcerias com fontes externas, outras instituições, universidades, institutos de pesquisa e empresas que, de forma colaborativa, asseguram um modelo de "empresa estendida". Outro fator apontado por Levy (2003), quanto ao gerenciamento das fontes de conteúdo, é a relação das instituições educacionais e professores conteudistas no que se refere aos direitos autorais e de propriedade intelectual. Nos Estados Unidos, por exemplo, essa relação com o detentor do direito autoral é prevista no contrato de trabalho e, usualmente, quando os autores são contratados como instrutores em tempo integral. Nos termos legais, o material didático produzido (notas de aula, provas, apostilas) é considerado "obra de aluguel" por 75 ou até 100 anos, a contar da data, em que o trabalho foi publicado ou criado. O estudo de Amorim e Piva Junior (2012) sobre os direitos autorais em EAD no Brasil elucida vários aspectos da Legislação nacional em situações de ensinoaprendizagem online. Os autores expõem situações ideais, aceitáveis e aquelas em que uma autorização é imprescindível. A situação ideal no trabalho de preparação de conteúdo em EAD é utilizar obras distribuídas sobre licenças CC (Creative Commons) ou de domínio público, bastando, logicamente, citar a fonte da obra e respeitar eventuais restrições. As instituições de ensino empenhadas em construir esse novo modelo de negócio em EAD devem estudar as leis de direitos autorais em vigor no País, evitando, desta forma, impasses legais.

b) Criação do programa/curso: segundo Moore e Kearsley (2008), o preparo de um curso em EAD requer as atividades do especialista no assunto e profissionais da área da instrução que organizem o conteúdo, de acordo com a teoria e a prática da gestão da informação e das teorias da aprendizagem. O enfoque inovador que se sugere nesse subsistema é o uso das tecnologias da informação e comunicação (TICs) que devem ser corretamente aplicadas na prática didático-pedagógica para garantir o sucesso do curso na modalidade a distância. Nesse aspecto, D'Avila, Epstein e Shelton (2007) afirmam que o processo de inovação tem respaldo nas mudanças tecnológicas de novos produtos, serviços e processos que envolvem materiais e equipamentos e nas 
[...] tecnologias capacitadoras que capacitam a empresa a executar sua estratégia com maior rapidez e melhor tempo de alavancagem como uma fonte de vantagem competitiva [...] (D’AVILA; EPSTEIN; SHELTON, 2007, p. 55).

Essas três formas caracterizam a mudança tecnológica no processo de inovação, e, para a criação do curso a distância, a utilização consciente das novas TICs e das ferramentas computacionais emergentes devem integrar o modelo de inovação e didático-pedagógico da instituição educacional. Moore e Kearsley (2008) afirmam que, para a gestão da qualidade de um curso online, também é necessário planejar a estrutura do curso para que envolva alguns fatores fundamentais de comunicação, como a notificação para os alunos: sobre o programa para identificar se possuem a automotivação e o compromisso para EAD e se possuem acesso à tecnologia requerida; sobre os objetivos, conceitos, ideias e resultados esperados do aprendizado no curso; sobre o acesso a recursos suficientes de biblioteca virtual acessível na WWW, sobre o corpo docente e sobre as expectativas envolvendo o tempo para término das tarefas e resposta dos professores. Quanto ao oferecimento de serviços ao aluno, Levy (2003), apoiado em autores como Moore e Kearsley (1996), afirma que a tecnologia não pode ser introduzida no ensino sem alterar a estrutura organizacional. Portanto, mais atenção deve ser dada aos serviços oferecidos a estudantes, pois o sucesso do curso depende do apoio que os alunos conseguem obter da instituição. Esse projeto de curso em EAD deve incluir apoio em âmbito fiscal, pessoal, acadêmico, jurídico, tecnológico e de infraestrutura, pois não basta os administradores investirem no desenvolvimento de cursos online sem preocupar-se com as necessidades do aluno para atender às próprias demandas, como consulta e acesso a material bibliográfico, serviços de secretaria e administrativos para resolver questões como matrícula, inscrição em disciplinas, declarações, aconselhamento online, etc. Segundo Levy (2003), as instituições enfrentam um dilema no planejamento de EAD, porque estão divididas entre querer servir os estudantes online e a necessidade de continuar a apoiar os seus serviços para os estudantes tradicionais. Porém, a realização de cursos online exige uma reorganização das formas em que os serviços de apoio são prestados, garantindo o mais alto padrão de suporte para os recursos disponíveis e evitando, assim, a possibilidade de aumento de custos.

c) Mídia, transmissão e disposição do material didático: para Moore e Kearsley (2008), a comunicação entre instituição educacional e o aluno deve ocorrer por intermédio de tecnologia, possibilitando que todo tipo de mensagem seja entregue a todos os alunos. A perspectiva dos autores sobre esse subsistema é que a utilização de várias tecnologias alternadas ou simultaneamente pode estabelecer maior qualidade na transmissão e disponibilização do material do curso. Inclusive o estudo do Institute for Higher Education and Policy, citado por Moore e Kearsley (2008), e que identificou 24 fatores que representam os marcos de referência significativos da qualidade de cursos na modalidade a distância baseada na internet. Dentre esses, se destaca o apoio institucional que abrange os seguintes fatores: plano de tecnologia bem estruturado que inclui medidas de segurança eletrônica instalado para assegurar padrões de qualidade, integridade e validade das informações; confiabilidade no sistema de veiculação da tecnologia; sistema centralizado que oferece suporte para criar e manter a infraestrutura da modalidade EAD. O enfoque inovador desse subsistema deve prever a concepção detalhada de um aparato ou dispositivo de comunicação e transmissão de dados eficiente e que permita a exploração simples e rápida do conhecimento disponível. Conforme Tidd, Bessant e Pavitt (2008, p. 33), os projetos para gestão da inovação podem "[...] ser derivados, de tecnologia de ponta, plataforma, de P\&D e alianças ou colaborativos entre empresas". Em EAD o trabalho de transmissão e disponibilização do material do curso deve ser minuciosamente calculado, pois envolve investimento em infraestrutura, capacitação e treinamento da equipe de técnicos, docentes e alunos. Essa visão compartilhada na gestão de projetos em inovação é fundamental para o comprometimento da equipe com objetivos gerais ou metas claramente definidas. Tidd, Bessant e Pavitt (2008) citam as ferramentas de apoio disponíveis para otimizar o processo de gestão da inovação e que são similares no âmbito da criação de um curso em EAD. Esses instrumentos incluem: ferramentas computacionais (ambientes de simulações e objetos de aprendizagem); tecnologias para construção de protótipos (jogos interativos que possibilitam a criação de réplicas físicas de uma ideia compartilhada); metodologia síncrona ou assíncrona para explorar a interação entre os participantes e colaboradores; regras de design (para identificação da marca da instituição de ensino); sistema de gestão da informação do produto/ cursos (mecanismos para gerenciar as melhorias no compartilhamento de informações e experiências com a criação de banco de ideias ou de modelos).

d) Interação e o papel dos instrutores: a comunicação entre aluno e instituição, em especial com os tutores, depende da natureza e da extensão da interação que, por sua vez, varia também de acordo com a filosofia organizacional, da visão dos criadores de curso, da maturidade dos alunos, da localização e da tecnologia utilizada nos cursos (MOORE; KEARSLEY, 2008). A gestão da inovação nesse subsistema pode ser repensada em um modelo de instrução individualizada, em que o aluno tenha o perfil reconhecido pela instituição e consiga planejar o estudo de acordo com seus interesses e necessidades 
imediatas. Algumas instituições americanas já seguem esse modelo de instrução e oferecem aos alunos condições de escolha para disciplinas e grades curriculares flexíveis que permitem o planejamento do tempo e da formação para cursos em EAD. Contudo, segundo os marcos de qualidade em curso online de Moore e Kearsley (2008), a instituição deve oferecer apoio aos instrutores sob os seguintes aspectos: auxílio técnico para o desenvolvimento do curso, assim como incentivo para o uso de novas ferramentas computacionais; apoio para a transição do ensino presencial para a instrução online; treinamento e assessoria durante o planejamento, desenvolvimento e finalização do curso e a distribuição de material impresso para que os instrutores possam lidar com questões dos alunos relativas ao uso de dados acessados eletronicamente.

Para Levy (2003), dispor o atual modelo educacional em formato digital não é suficiente para o planejamento de programas em EAD. Os professores e instrutores devem estar cientes de todos os detalhes do curso em um ambiente virtual de aprendizagem. Assim, além da inovação no currículo, os professores conteudistas e instrutores precisam desenvolver: flexibilidade para ensinar e repassar o conhecimento; habilidades interpessoais para se comunicar eficazmente com os alunos online; domínio da tecnologia requerida para manuseio de hardware e software; competência para ajudar os alunos a superar problemas com a tecnologia; conhecer as especificações técnicas do material didático, arquivos e demais recursos computacionais que dependem da capacidade de memória e velocidade da rede de comunicação.

A construção da organização inovadora, segundo Tidd, Bessant e Pavitt (2008, p.25) depende do “[...] trabalho em equipe e da combinação criativa de diferentes disciplinas e perspectivas [...]". Um subsistema de interação guiado pelos princípios da inovação requer também a articulação de uma nova visão e envolvimento por parte dos gestores da instituição em assumir projetos de EAD, que, mesmo gerando retornos de longo prazo, possibilitam penetração e crescimento do mercado futuro, sem, contudo comprometer os princípios da qualidade. Referindo-se à qualidade, a instituição educacional deve prever o controle e a avaliação contínua do aluno, verificando os resultados da aprendizagem em intervalos regulares que possibilitem o uso de mecanismos de feedback imediato aos interessados para correção do processo e do fluxo da informação. Esses requisitos também são apontados por Moore e Kearsley (2008) como um dos marcos da qualidade em cursos online que envolvem os aspectos do processo de ensino-aprendizagem para a interação dos alunos com o corpo docente, facilitada por diversos meios (correio e/ou e-mail); feedback (em tempo hábil) das tarefas e das questões postadas pelos alunos; e as instruções para os alunos sobre os métodos adequados de pesquisa, incluindo a avaliação da validade dos recursos.

e) Ambientes Virtuais de Aprendizagem (AVAs): segundo Moore e Kearsley (2008), os ambientes de aprendizagem controlados pela instituição exercem impacto considerável sobre a eficácia dos sistemas e subsistemas. $\mathrm{O}$ ambiente deve ser acessível aos alunos em lugares e momentos diferentes para viabilizar a transmissão do conteúdo do curso e promover a interação entre alunos/alunos e alunos/tutores. Os próprios autores indicam que já existem iniciativas em instituições norte-americanas que utilizam os componentes do ambiente de aprendizagem de diferentes formas para transformar seus recursos e atingir maior portabilidade da informação e do conhecimento. As instituições de posse das inúmeras ferramentas computacionais e dos dispositivos emergentes que valorizam a tecnologia da informação e comunicação podem criar novos processos durante a gestão da inovação que contemplem as características evidentes deste público. Ressalta-se que os softwares educacionais comerciais, normalmente exploram os atrativos de um ambiente hipermídia (imagens, animações e áudio), mas acabam descuidando dos aspectos relacionados às demandas psicopedagógicas, adequadas ao perfil cognitivo do aprendiz online, tanto na fase do planejamento e construção dos conteúdos pedagógicos, quanto durante o processo de aprendizagem propriamente dito (SOUTO, 2003).

Levy (2003) ressalta também que, mesmo de posse de AVAs bem estruturados, as instituições devem zelar pela própria missão, pois um programa de EAD não pode ser implementado sem o desenvolvimento simultâneo do plano curricular junto ao apoio dos corpos docente e técnico. Esse cuidado pode evitar custos desnecessários, perda de tempo, confusão, frustração e estresse para todos os envolvidos.

f) Perfil do aluno em EAD: os interesses dos alunos por cursos online também estão relacionados à liberdade de escolha do AVA para o estudo. Em sua maioria, esses alunos estudam durante o trajeto que perfazem para o trabalho ou para casa, nos horários livres em que estão sentados em meios de transporte coletivo, como ônibus. Esse tempo livre é precioso para os alunos da EAD que aproveitam esses momentos para o estudo e a interação nos cursos, pois, geralmente, desenvolvem muitas outras atividades paralelas, como trabalho, etc.

A gestão da inovação para esse subsistema do planejamento estratégico deve prever, por exemplo, o uso das estratégias do M-Learning (Mobile Learning), utilizando dispositivos móveis, equipamentos como micronotebooks e palmtops (TAROUCO et al., 2004). Essa portabilidade da informação e do conhecimento facilitam a interação e a transmissão do conteúdo, aumentando a satisfação do aluno e a qualidade 
nos resultados finais. Segundo Moore e Kearsley (2008), a instituição deve realizar a entrega ao aluno de informações relevantes sobre programas, requisitos para admissão, orientação, taxas, livros, suprimentos, exigências técnicas e serviços, assim como treinamento prático para acesso ao conteúdo, arquivos, mídias eletrônicas e serviços de informações diversos. Porém, outro fator apontado por Levy (2003) e que influencia negativamente o desempenho do aluno durante cursos online é a falta de domínio e despreparo para a aprendizagem e uso de recursos do ambiente virtual.

Levy (2003) afirma que os alunos que dispõem de sistemas de apoio como tutoria online, aconselhamento e grupos de estudo são mais propensos a obter sucesso em suas aulas de EAD. Segundo Levy (2003), as instituições de ensino deveriam incluir no planejamento estratégico componentes-chave para cursos online, como os serviços aos estudantes (treinamento e suporte), projetos de e-commerce, livrarias, recolhimento de mensalidades online e o plano de expansão tecnológico. Essas iniciativas remetem à maior diversificação de serviços ao cliente-alvo, que passarão a ser atendidos também por fornecedores externos, por exemplo, livrarias virtuais que atuam junto às faculdades e estabelecem um novo modelo de negócio, e ainda técnicos especialistas autônomos que, sem vínculo com a instituição, dispõem suas aulas no AVA e prestam um novo tipo de serviço (LEVY, 2003).

\section{Modelo de negócio para a Educação a Distância}

O trabalho de D'Avila, Epstein e Shelton (2007) desmistifica algumas convicções equivocadas sobre inovação e propõe os instrumentos e processos para que uma organização possa realizar a gestão da inovação com base no modelo estratégico. Segundo esses autores, o novo modelo depende da sustentação da organização em combinar as mudanças em tecnologias e no modelo de negócios. Os autores apontam que as alavancas para a mudança do modelo de negócios para a gestão da inovação são a proposição de valor, a cadeia de suprimentos e o cliente-alvo.

Procurando estabelecer um paralelo entre as organizações que oferecem produtos, serviços e bens de consumo e as instituições que atuam no mercado educacional, percebe-se que o paradigma a ser derrubado é a forma tradicional com que os dirigentes conduzem o processo de gestão estratégica e de tomada de decisão. Para as instituições educacionais que organizam o modelo de negócio focado na inovação e no relacionamento com os alunos, parece natural o uso de novas tecnologias e/ou ferramentas computacionais. No entanto, para se firmar um processo estratégico da inovação nessas instituições inexperientes, o modelo de negócio deve ser balizado pelas condições da proposição de valor, da cadeia de suprimentos e o cliente-alvo:

a) Proposição de valor: para D'Avila, Epstein e Shelton (2007), proposição de valor representa o que é vendido e lançado no mercado pela empresa. Para a EAD, essa proposição pode representar o curso propriamente dito a ser elaborado e oferecido pela instituição, que tem a oportunidade de lançar um produto inteiramente novo ou a melhoria de algo que já existe. Nesse aspecto, nota-se que o grande desafio para essas instituições é inovar na oferta de um curso que tenha qualidade e que atenda às necessidades específicas de seus alunos ou de mercado. As empresas fornecedoras do mercado de EAD atendem como clientes preferenciais o setor privado, com ampla margem de diferença se comparado a empresas públicas, governos, ONGs e instituições públicas. (ANUÁRIO..., 2007). Para garantir a inserção no mercado, as instituições de ensino podem buscar parceria com essas empresas e estabelecer um contrato de transferência de tecnologia para interagir e aprender com os alunos e os concorrentes.

No entanto, Tidd, Bessant e Pavitt (2008) citam 5 habilidades essenciais à transferência tecnológica (construção e manutenção de uma rede de relacionamentos de fontes tecnológicas; seleção; negociação, implementação e aprendizagem). A transferência de tecnologia depende também da realização de parcerias com fontes externas, universidades, institutos de pesquisa e outras empresas que, de forma colaborativa, asseguram um modelo de "empresa estendida". Segundo os autores, algumas ferramentas ajudam na tomada de decisão estratégica para a transferência de tecnologia e para facilitar a implementação do processo de inovação, o que requer estabelecer um processo gradual de redução de incerteza por meio de uma série de estágios de solução de problemas, conectando o mercado e os fluxos de tecnologia relacionados na trajetória.

Na prática educativa online, percebe-se a resistência por parte dos gestores e professores em assumir a experimentação no processo de construção de outras formas didáticas e pedagógicas no processo ensinoaprendizagem. Segundo o especialista Litto (2010), o Brasil não é muito inovador em EAD, pois ainda apresenta muitos resquícios de conservadorismo, principalmente em assuntos como aprendizagem e experimentação na cultura luso-brasileira. Gestores e órgãos governamentais e empresas não encorajam a experimentação e inovação. Litto (2010) considera que essa situação venha a mudar quando os alunos que hoje fazem EAD alcançarem posições de liderança na sociedade brasileira.

b) Cadeia de suprimentos: segundo D'Avila, Epstein e Shelton (2007, p. 53), cadeia de suprimentos é a "[...] maneira pela qual a entidade organiza, 
compartilha e opera a fim de produzir e entregar seus produtos e serviços".

O gerenciamento da cadeia de suprimentos ou supply chain management (SCM) é uma estratégia de negócio que visa o aumento do valor da cadeia e de seus clientes, pela otimização do fluxo de produtos, serviços e informações relacionadas. Sobre o gerenciamento da cadeia de suprimentos na EAD pode-se afirmar que é necessário, além do aporte das ferramentas da tecnologia de informação, considerar todos os atores envolvidos no processo de produção dos cursos online, como professores, tutores, gestores, técnicos, secretaria executiva, equipe de profissionais do setor jurídico, financeiro e administrativo de forma geral. Para o gerenciamento da cadeia em EAD, também é fundamental considerar outros processos como a previsão de demanda, o relacionamento com fornecedores, planejamento e programação das operações de desenvolvimento e implementação de plataformas e ferramentas computacionais que instrumentalizam os cursos e aulas online. Todo o padrão de entrega de um curso deve ser planejado, visando facilitar a comunicação e promover a usabilidade da plataforma pelos alunos e facilitadores que trabalham, respectivamente, como consumidores e fornecedores para esse segmento. Para a otimização do processo e do gerenciamento da cadeia de suprimentos em EAD, as configurações de rede e os aspectos da comunicação mediada pelo computador devem ser detalhadamente calculados, visto que alguns programas e plataformas podem sobrecarregar o fluxo de envio e recebimento de dados, que, por sua vez, estão diretamente relacionados às condições de infraestrutura da rede externa e do equipamento disponível para o aluno e para a instituição.

O gestor no processo de planejamento estratégico da cadeia de suprimentos em EAD deve considerar, além das possíveis restrições de recursos e infraestrutura, as políticas de direitos autorais e de propriedade intelectual que regem as relações contratuais com seus fornecedores (professores conteudistas). $\mathrm{O}$ aspecto jurídico desta questão influencia a execução de toda a entrega do produto, no caso do curso ao cliente final. O processo de entrega de material didático impresso, divulgação de vídeos, apresentações, textos e outros recursos didáticos deve prever a criação de rotinas e protocolos minuciosos acordados pelas partes interessadas e registradas na instituição como patrimônio intangível. A execução de toda cadeia de suprimentos em EAD deve prever ainda o desenvolvimento da atividade de controle de utilização e satisfação, pois não basta apenas entregar o material/curso ao aluno sem gerenciar e controlar o retorno ou feedback que aponte se o processo de ensino-aprendizagem se concretizou. Desta forma, várias ferramentas já são utilizadas pelos Ambientes
Virtuais de Aprendizagem (AVAs) ou plataformas de EAD, no entanto, a instituição deve ir além e estudar a implantação de "robôs" que controlem automaticamente o uso e as dificuldades de todos os atores no uso do sistema de entrega online do curso.

c) Cliente-alvo: a identificação do segmento de clientes é fundamental para o desenvolvimento do processo de inovação no modelo de negócio da instituição educacional. Toda a sistemática para divulgação/marketing, venda e distribuição dos cursos a distância deve estar centrada nas características e necessidades deste público. O gestor e sua equipe devem prever mudanças na relação com o cliente-alvo quando as novas tecnologias, plataformas ou sistemas forem oferecidos como oportunidades para inovar. O grande "termômetro" de satisfação e eficiência destas ferramentas tecnológicas, com certeza, será o cliente-alvo, aluno ou usuário.

O crescimento da EAD (2004-2007) foi de 24,9\% no número de alunos e de $14,2 \%$ de instituições que ofertam a modalidade. Os dados referentes à quantidade de alunos em projetos credenciados mostram que nos últimos três anos o número de alunos em EAD cresceu 213,8\% e o de instituições credenciadas, 54,8\% (ANUÁRIO..., 2007). O perfil dos alunos da EAD no Brasil apresenta as seguintes características: quanto aos aspectos do gênero humano, o sexo masculino é predominante para os cursos de educação básica/técnica/EJA (credenciamento estadual) e o sexo feminino para cursos de graduação e pós (credenciamento federal); quanto à idade média dos alunos, prevalece o número de estudantes com mais de 30 anos de idade, ou seja, 35,8\% das instituições da amostra ou para exatamente $50 \%$ das 100 instituições que responderam a esta pergunta; quanto à faixa etária: 1/3 dos alunos a distância estão na faixa etária entre 30 e 34 anos, ou seja, $32 \%$ dos respondentes; quanto à faixa de renda: $29 \%$ dos alunos têm renda entre 1 e 3 salários mínimos, contra apenas $21 \%$ com renda superior a 3 salários mínimos (ANUÁRIO..., 2007).

Os agentes em Educação a Distância compreendem os tutores, professores e alunos e, assim como na educação tradicional, desempenham funções essenciais no processo de ensino-aprendizagem. Porém, algumas características distinguem-se entre eles e a modalidade a distância, como: na modalidade presencial o aluno pode até ser um receptor passivo, mas na modalidade a distância precisa ser ativamente interessado no processo de aprendizado, pois é corresponsável pelo sucesso do próprio processo de aprendizagem (PRETI, 2005). O papel do professor em Educação a Distância, segundo Salmon (2000), apesar das diferenças, denominações como "E-Moderador" e "Facilitador" ainda mantêm sob sua responsabilidade o papel de incentivar as atividades individuais e em grupo, motivando os alunos à interação, reflexão 
e busca constante de novos conhecimentos. Do professor, como facilitador do processo de ensinoaprendizagem são requeridas inúmeras competências descritas por Belloni (2001), como um conjunto de conhecimentos, habilidades e atitudes que capacitam um profissional a desempenhar as suas tarefas de forma satisfatória, tomando como critério avaliativo os padrões esperados em um determinado momento, em uma determinada cultura. Para a autora, há um novo papel do professor na Educação a Distância, o de constituir-se em um parceiro dos estudantes no processo de construção de conhecimento. Para a autora, são três as dimensões dos saberes docentes: (i) Pedagógica (orientação, aconselhamento e conhecimentos do campo específico da Pedagogia); (ii) Tecnológica (utilização de estratégias tecnológicas na educação); (iii) Didática (formação específica do professor em determinados campos científicos, com necessidade constante de atualização, além das competências pessoais de cada um).

Para Palloff e Pratt (2002), as recentes teorias elaboradas nos círculos educacionais postulam que os alunos constroem ativamente o conhecimento e o significado por meio da experimentação, da exploração, da manipulação e do teste de ideias na realidade. A interação e o retorno dos outros colegas e do professor/tutor ajudam-no a determinar a exatidão e a pertinência das ideias. Desta forma, atividades em grupo, simulações e uso de questões abertas são forças poderosas no processo de aprendizagem online.

A tecnologia educacional contemporânea reconhece, na modalidade de ensino a distância, o meio profícuo para o uso e planejamento de ferramentas tecnológicas para a gestão do conhecimento e dos sistemas de informação, permitindo aos indivíduos dispersos geograficamente construírem o conhecimento coletivo e individual e aperfeiçoar o potencial de aprendizagem, interação e produção (ARAUJO, 2009, p. 20).

O Ensino a Distância propõe novas abordagens e competências do professor e do aluno, com o objetivo de que o professor aja como um facilitador, incentivando e cuidando dos alunos ao longo do processo de aprendizagem, cujas diretrizes e estruturas foram construídas coletivamente (PALLOFF; PRATT, 2002). Uma importante interrelação se estabelece na prática educativa entre o tutor/orientador (que representa alguém que indica caminhos, que tem como função possibilitar a mediação do saber); o sujeito ativo do processo educativo (aluno que busca ressignificar e reconstruir concepções e práticas dos saberes); e as ferramentas do ambiente virtual (meio facilitador da aprendizagem). Porém, o sucesso da prática educacional a distância ou apoiada em ambientes virtuais depende também da elaboração de um projeto pedagógico coerente, flexível e sistêmico, que gerencie inúmeras variáveis, levando em consideração, o contexto sociocultural dos alunos e da instituição em que se insere.

Sobre a relação entre os colaboradores para inovação em EAD pode-se referenciar o estudo de Tidd, Bessant e Pavitt (2008), que apontam para a importância do envolvimento do grupo para promover mudanças incrementais sustentado pela cultura organizacional de apoio e estímulo a longo prazo. O desempenho intensificado pode resultar do aumento de envolvimento na inovação por meio da "inovação com alto envolvimento". Nesse aspecto, pode-se afirmar que, em EAD, o envolvimento da equipe de docentes e técnicos que devem apoiar a implementação da inovação na organização é fundamental, no entanto, além do envolvimento e da quebra de paradigma por uma aceitação por parte da equipe organizadora, deve-se cuidar da capacitação e treinamento adequado para atuação nessa modalidade de ensino.

\section{Níveis da inovação}

Existem 5 estágios ou níveis da inovação com alto envolvimento citados por Tidd, Bessant e Pavitt (2008), sendo que: no nível 1, a inovação é uma atividade inconsciente e aleatória e os indivíduos trabalham em conjunto para resolver problemas e dificuldades; no nível 2, a inovação envolve o estabelecimento de um processo formal para solucionar problemas de forma sistemática e estruturada; no nível 3, acontece a união do hábito da inovação com os objetivos estratégicos da organização; no nível 4, ocorre o fortalecimento dos indivíduos e dos grupos para experimentar e inovar a partir das próprias iniciativas; no nível 5, configura-se uma situação em que todos estão plenamente envolvidos em experimentar e melhorar as coisas, compartilhando conhecimento. $\mathrm{Na}$ figura 2 nota-se que para assegurar a gestão estratégica da inovação na EAD, a organização também pode utilizar os 5 estágios ou passos firmados por Tidd, Bessante e Pavitt (2008) que abrangem as seguintes proporções:

Nível 1- Inovação inconsciente e aleatória: após a realização de treinamentos e a inserção da equipe de professores e técnicos no contexto da EAD, pode-se colocar situações problemas para que, colaborativamente, todos repensem os processos e produtos disponíveis na organização e passem a propor mudanças e soluções que, em princípio, podem gerar um baixo impacto associado, mas que, no entanto, incentivam e motivam a equipe para os desafios futuros da gestão estratégica da inovação.

Nível 2- Estabelecimento de um processo formal para o envolvimento da equipe com a inovação: nesse nível, a organização deve sustentar, por meio de infraestrutura e projetos sistemáticos, o 


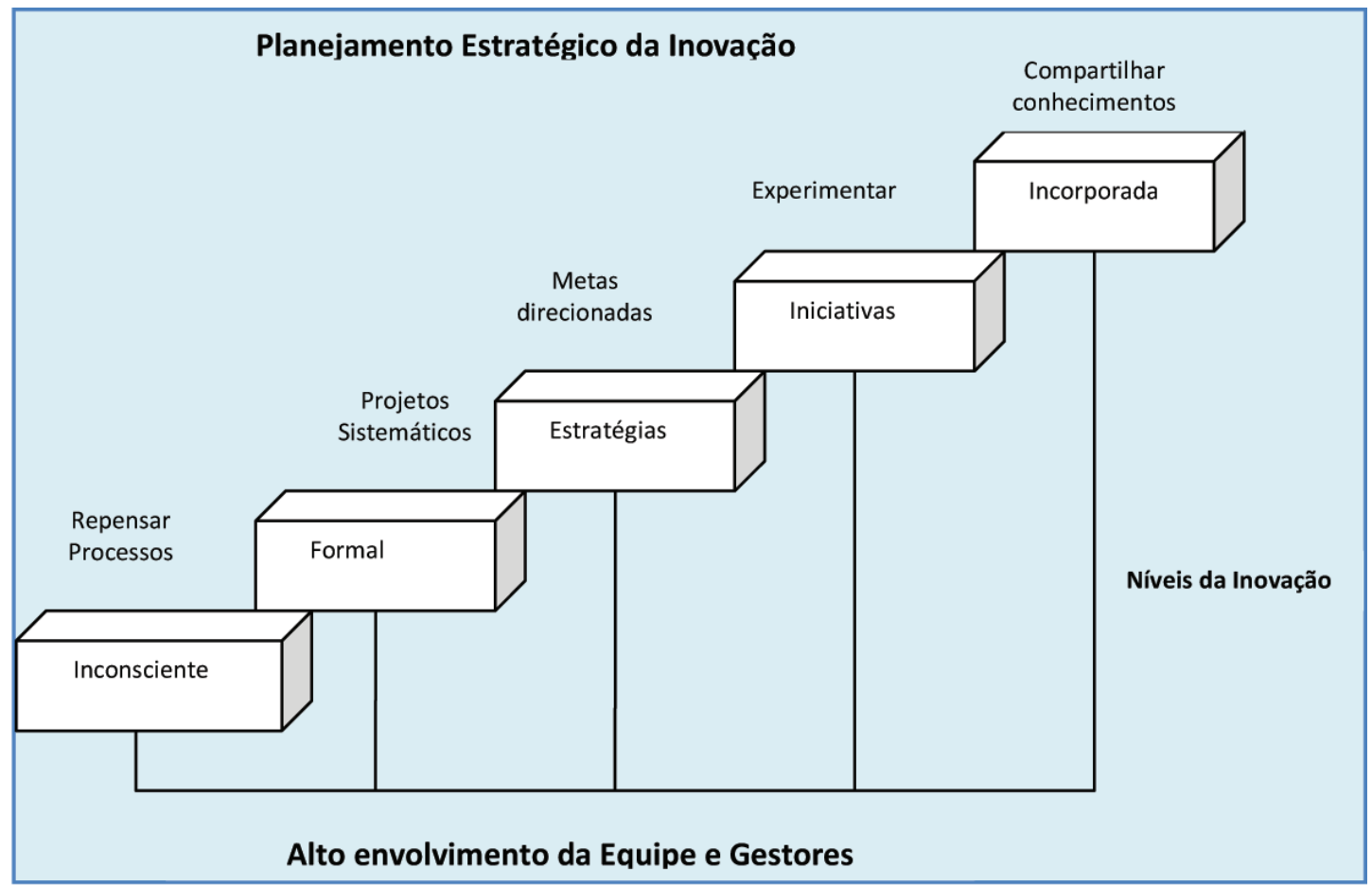

Figura 2. Relação dos níveis de inovação e o envolvimento da equipe e gestores em um planejamento estratégico para inovação. Fonte: Tidd, Bessant e Pavitt (2008, p.136).

desenvolvimento pela equipe no processo de inovação, ou seja, formalizar as rotinas e processos oriundos dessas novas atividades educativas, despendendo recursos pedagógicos e tecnológicos que possibilitem a viabilidade das inovações em estudo.

Nível 3- Incorporação do hábito da inovação com os objetivos estratégicos da organização: neste nível, o hábito da inovação está vinculado intrinsecamente às metas e atividades estratégicas da organização envolvida na EAD. O envolvimento dos gestores e da equipe de inovação fica visível nos produtos e serviços oferecidos pela organização e, inclusive, nos recursos financeiros aplicados pela organização na área de EAD. Esse desdobramento estratégico agrega valor a todo o processo de gestão da inovação e, como qualquer outro procedimento sistemático na organização, deve contar com monitoramento e mensuração periódicos por parte dos gestores, da equipe de EAD e dos usuários ou alunos.

Nível 4- Inovar a partir das próprias iniciativas: neste nível, a equipe de EAD, junto a princípios da inovação estratégica já maturados e consolidados, têm condições de experimentar e inovar a partir das iniciativas anteriores. Isso é possível, pois, mediante os resultados obtidos, a interação com os usuários ou alunos, as próprias impressões e insights da equipe de EAD podem viabilizar determinados produtos e serviços na modalidade, vinculando-se a todo o planejamento estratégico da instituição.
Nível 5- Equipe plenamente envolvida em experimentar e melhorar a divulgação de conteúdos, compartilhando conhecimento. Essa situação é plenamente possível em EAD se todos os níveis anteriores foram ultrapassados com a aprovação, envolvimento e acompanhamento dos gestores, equipe técnica, suporte financeiro, tecnológico, administrativo, professores, especialistas, tutores e demais membros internos e externos que acompanham o desenvolvimento de um plano de Educação a Distância na instituição. Neste nível é fundamental a constituição de um banco de modelos ou de melhores práticas que deverão compor o conhecimento implícito de todas as atividades desenvolvidas no planejamento do curso, ou seja, deve-se compor um banco com relatórios sistematizados das práticas: didáticopedagógica, financeira, administrativa, marketing e comunicação, secretaria executiva, recursos humanos, controle de qualidade, tecnológica e midiática, assim como os relatos de casos e o conjunto de FAQs (Frequently Asked Questions) enviadas pelos alunos que se configuram como fontes preciosas de pesquisa e opinião para melhoria de produtos e serviços.

\section{As regras da inovação para a Educação a Distância}

Segundo D'Avila, Epstein e Shelton (2007), existem 7 regras básicas da inovação que são "interdependentes", e o uso de todas é imprescindível 
para conduzir a organização a um caminho de sucesso. $\mathrm{Na}$ tentativa de estabelecer o paralelo entre as regras de inovação citadas por D'Avila, Epstein e Shelton (2007) e os pressupostos de Moore e Kearsley (2008) para a EAD, apresenta-se um ensaio descritivo das correlações previsíveis para uma instituição de ensino empenhada na gestão da inovação na EAD. Regra 1 - O gestor motiva, sustenta e recompensa a equipe para as decisões de inovação e a instituição adota uma política definida para a EAD, destinando recursos, capacitação e incentivos governamentais para os colaboradores e público-alvo. Regra 2 - Integrar a inovação à mentalidade do negócio: a inovação deve ser parte integral do processo operacional diário da empresa. Todos os setores da instituição devem sustentar a inovação e acompanhar o seu ritmo. Regra 3 - Alinhar a inovação com a estratégia da empresa. Determinar os tipos e a quantidade de inovação necessários para dar suporte à estratégia do negócio. Adequar a estratégia de inovação à missão e visão da instituição educacional. Regra 4 - Administrar a tensão entre criatividade e captação de valor. A criatividade deve ser transformada em lucro (execução e captação de valor). Identificar o potencial da proposta de inovação e realizar pesquisa de mercado. Regra 5 - Neutralizar os anticorpos organizacionais. A inovação exige mudança e desperta rotinas e normas culturais contrárias. Envolver a equipe para evitar a ação contrária. Regra 6 - Cultivar uma rede de inovação além dos limites da organização: fundir recursos internos com outros grupos ou parceiros. Buscar parcerias com outras instituições para desenvolvimento de produtos e serviços. Regra 7 - Criar os indicadores de desempenho e as recompensas adequadas à inovação. O nível de inovação está relacionado ao estímulo/recompensas dados às pessoas. Incentivar a equipe, pois a tarefa em EAD exige dedicação e envolvimento. Ressalta-se, no entanto, que esse quadro é apenas um esboço diante da complexidade do assunto que merece outro trabalho específico que venha a relacionar, em detalhes, as regras de inovação em EAD no contexto das instituições de ensino nacionais, verificando, inclusive, as iniciativas governamentais recentemente adotadas para garantir a qualidade, estipular regras e sistemas de avaliação para EAD no Brasil.

\section{Mapeando a inovação na EAD}

Segundo Tidd, Bessant e Pavitt (2008), as duas teorias ou escolas sobre estratégias para inovação existentes são a racionalista e a incrementalista. Pode-se notar que as instituições de ensino superior, empenhadas em desenvolver estratégia para inovação em EAD, ainda apostam em metas incrementalistas, pois possuem um conhecimento imperfeito do cenário e de suas forças e fraquezas para enfrentar os possíveis índices e direções de mudanças futuras.
Os gestores de cursos online conduzem o planejamento segundo uma lógica de análise de "tentativa e erro" ou "prove e aprove", medindo e avaliando os efeitos de determinada medida, conforme a necessidade.

Para Tidd, Bessant e Pavitt (2008), os projetos de inovação envolvem certo grau de incerteza que exige alto grau de flexibilidade e criatividade, integração de conhecimento, equipes multidisciplinares, simulação e uso de tecnologias de exploração, com a finalidade de prever problemas futuros e reduzir prazos e custos, aumentando a qualidade. Na prática dos cursos de EAD, a gestão da inovação deve procurar desenvolver novos produtos e processos sistemáticos, envolvendo, simultaneamente, toda a estrutura disponível na empresa ou nas parceiras para implementar um projeto de ensino que conte com o apoio da equipe de trabalho, utilize adequadamente as ferramentas de suporte para aprendizagem organizacional e, finalmente, apresente para o aluno os resultados de melhoria.

Tidd, Bessant e Pavitt (2008) consideram que os benefícios potenciais das atividades de inovação são: o lucro extra obtido com o aumento das vendas para novos produtos e o conhecimento empresarial acumulado (ativos intangíveis), que podem ser úteis para o desenvolvimento de inovações futuras. Quanto à forma de avaliar o aprendizado, algumas técnicas convencionais não podem avaliar opções que são, no caso, oportunidades criadas pela empresa para apostar em um investimento aparentemente rentável. Em EAD, para mapear a inovação há necessidade de verificar os indicadores e métricas balizadores do processo de avaliação. No âmbito nacional, a Secretaria de Educação a Distância do Ministério da Educação tem focado os padrões de qualidade em um documento oficial para cursos a distância e as recentes reformulações normativas, que aprimoram as condições de avaliação para credenciamento de instituições que queiram oferecer cursos a distância, inclusive os de educação continuada (BRASIL, 2007).

Desta forma, procura-se estabelecer uma correlação conceitual entre os indicadores de inovação em produtos e serviços, em empresas de bens de consumo e na métrica de inovação de cursos em EAD, ressaltando, no entanto, que se trata de uma especulação, pois, no Brasil, a pesquisa na área ainda é incipiente. Especificamente sobre os indicadores e métricas para mensurar a qualidade de um curso de EAD, Longo (2006) destaca os seguintes fatores: conteúdo (clareza, hipertextualidade, hipermodalidade); tutoria (coaching, orientação, disponibilidade, integração); ambiente colaborativo (chat, pesquisa à biblioteca virtual, fóruns, encontros presenciais); desenvolvimento de competências (leitura, comunicação escrita, análise e síntese de ensaios).

No entanto, o documento oficial da Secretaria de Educação a Distância, do Ministério da 
Educação indica por meio de abordagem sistêmica algumas dimensões que conferem à criação de cursos online maior complexidade, envolvendo os aspectos pedagógicos, recursos humanos e infraestrutura (BRASIL, 2007). Esse referencial de qualidade nacional recomenda a elaboração de um Projeto Político Pedagógico para cursos a distância que devem contemplar os seguintes tópicos: concepção de educação e currículo no processo de ensino e aprendizagem; sistemas de comunicação; material didático; avaliação; equipe multidisciplinar; infraestrutura de apoio; gestão acadêmico-administrativa e sustentabilidade financeira. Os aspectos da inovação estão presentes na descrição de cada um dos elementos apontados, como a inclusão de novos modelos pedagógicos, mídias e veículos para transmissão e entrega do curso, desenvolvimento de novos recursos tecnológicos e ferramentas computacionais que apõem a interação e acessibilidade dos alunos ao conteúdo do curso.

Segundo Moore e Kearsley (2008), as instituições educacionais devem monitorar os seguintes fatores relacionados à qualidade: quantidade e qualidade de consultas e matrículas (acompanhamento das variáveis demográficas e socioeconômicas); sucesso dos alunos (obtenção de certificação em outras instituições); satisfação dos alunos (avaliação e comentários sobre o conteúdo, organização do curso, instrutores, materiais de instrução e sistema de veiculação); satisfação do corpo docente (avaliar o grau em que as estratégias de ensino e os materiais são eficazes, se os serviços de apoio aos alunos são adequados e se o curso atende às necessidades dos alunos e da instituição); reputação do programa ou da instituição (matrículas efetuadas, número de formandos satisfeitos com seus cursos e se os empregadores que os contratam estão satisfeitos com o desempenho no cargo); qualidade dos materiais do curso (produzir um material de qualidade e seguindo padrões estabelecidos pelos órgãos nacionais). Percebe-se que, nas perspectivas desses fatores, é possível integrar a gestão da inovação e o processo de envolvimento da equipe para garantir que fatores externos e internos de fracasso em cursos em EAD sejam controlados. Todo o processo de inovação deve incluir em suas atividades a captura ou a exploração do ambiente de seleção de possibilidades e o conhecimento sobre tecnologias, mercados, competidores e outras fontes (TIDD; BESSANT; PAVITT, 2008).

O processo de inovação em EAD no Brasil ainda é incipiente nas instituições de ensino superior, no entanto, nota-se a existência de um movimento constante para a detecção de tendências para criação de cursos online que alcancem as expectativas dos usuários finais, ou seja, dos alunos que atualmente possuem um perfil mais ativo e a capacidade de reconhecimento da aprendizagem por meios tecnológicos e midiáticos que incentivam o desenvolvimento de novos produtos e serviços. Segundo Cysneiros (1999), as novas tecnologias da informação e comunicação aplicadas na Educação, em muitos casos, representam uma "inovação conservadora".

Esse aspecto do uso da tecnologia educacional é fundamental para análise da relação da inovação em EAD e os pontos de virada para a produção de novos produtos e processos, de acordo com o sentimento popular ou mudanças do mercado. A política pública nacional, no início dos anos 80 , promoveu a inclusão dos recursos de informática na educação, "[...] no contexto mais amplo da reserva de mercado para informática [...]" (CYSNEIROS, 1999, p. 15). Essa iniciativa do governo brasileiro é apontada por Cysneiros (1999, p. 15) como uma forma de

[...] introdução da informática na escola como uma mistura de Informática na Educação e de preparação para o trabalho, tentando usos pedagógicos das ferramentas de software utilizadas fora da escola [...].

Nos anos 90, surge no Brasil a proposta de EAD como resposta à demanda crescente por formação superior para fundamentar o

[...] binômio que na Europa também havia alimentado um círculo virtuoso de desenvolvimento: crescimento econômico com melhor distribuição de renda [...] (CYSNEIROS, 1999, p. 15).

Nesse contexto, instala-se, nos principais centros universitários do País, o sistema da Universidade Aberta do Brasil (UAB) na tentativa de implementação de um consórcio interinstitucional que alavanque a modalidade de Educação a Distância, distribuída pela rede mundial de computadores (VAN DER LINDEN; AZEVEDO, 2010).

No entanto, os investimentos aplicados pelo governo brasileiro para a expansão do acesso à grande rede, em 2005, entre as classes A e B chegou a índices escandinavos de mais de $80 \%$ de penetração, porém, nas classes C, D e E, esse índice de penetração do acesso à internet não ultrapassou 5\%. Os investimentos em telecomunicações no Brasil esbarram em conduta invasiva e onerosa por parte dos dirigentes que dificultam, por exemplo, a penetração da banda larga para eliminar o gap de acesso em razão ao alto custo de instalação de redes para pessoas de baixa renda ou moradores de determinadas regiões onde o serviço nem existe. Além disso, o Brasil apresenta uma das maiores cargas tributárias do mundo, o que inviabiliza o aumento no número de usuários (IAQUINTO, 2010). Esses aspectos de infraestrutura de telecomunicações interferem drasticamente na evolução do plano de inovação em EAD das instituições de ensino, que se deparam com restrições básicas, como a ineficiência 


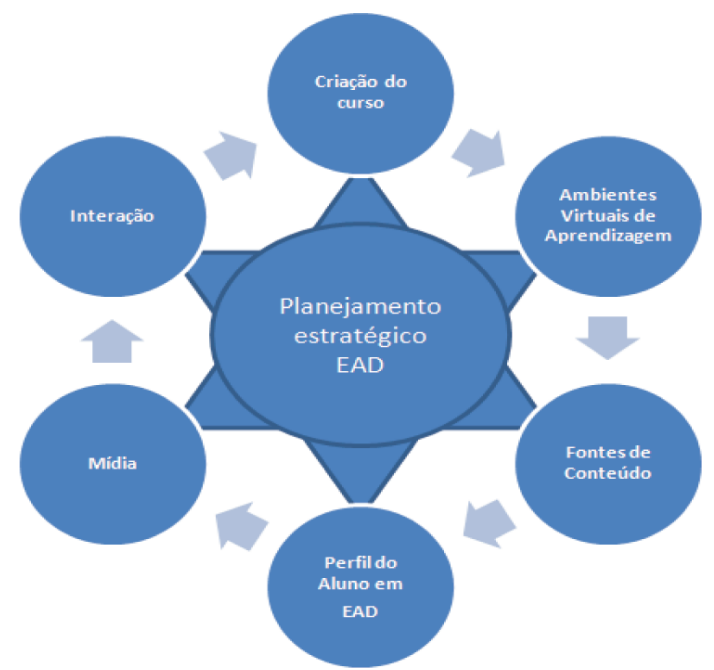

Figura 3. Gestão da Inovação em EAD e o novo modelo de negócio.

dos serviços públicos e privados para o acesso à internet banda larga de alta velocidade.

Para ilustrar o propósito reflexivo deste trabalho, demonstra-se na figura 3, o paralelo conceitual estabelecido entre os princípios do planejamento estratégico da EAD e a gestão da inovação para o século XXI. No círculo interno da figura 3, está representado o modelo de negócio e seus balizadores (proposição de valores, cadeias de suprimentos e cliente-alvo) que apoiam a movimentação e adequação dos subsistemas do planejamento estratégico (fontes de conteúdo, criação do cursos, Ambientes Virtuais de Aprendizagem, mídia, interação e perfil do aluno). Esses elementos são manipulados pelos gestores que utilizam as regras preestabelecidas e conduzem suas ações para obtenção dos mais elevados níveis de inovação. Esse procedimento sistemático, porém flexível, gera impacto significativo sobre os resultados da gestão da inovação e, consequentemente, fundamentam um novo modelo de negócio da instituição para EAD.

\section{Considerações finais}

O processo de inovação na Educação a Distancia depende intrinsecamente de um planejamento estratégico firmado em componentes e áreas interligadas que suportem mudança radical da estrutura da instituição e da cultura organizacional representada nos diferentes estratos do sistema de tomada de decisão e dos colaboradores. Da parte dos administradores, funcionários e do corpo docente, espera-se, durante o processo de inovação, uma postura de quebra de paradigmas e disposição para "experimentar" e/ou construir colaborativamente novas competências e saberes que aponham a criação de cursos a distância com qualidade, especificamente em Ambientes Virtuais de Aprendizagem. Quanto aos alunos, usuários desses programas inovadores em EAD, recomendam-se postura ativa de automotivação e interesse pela construção do conhecimento em comunidades virtuais de aprendizagem.

Obviamente os requisitos básicos para o desenvolvimento de cursos a distância nas instituições educacionais inovadoras devem incluir, no modelo de negócio, todos os subsistemas que interagem para que as estratégias pensadas sejam concretizadas com sucesso. $\mathrm{O}$ alto envolvimento da equipe e o investimento em recursos tecnológicos e midiáticos também são fatores essenciais para a estruturação dos elementos-chave do programa educacional na modalidade a distância. Os investimentos requeridos também extrapolam a ideia de simples compra de novas plataformas e incluem a expectativa de custo para o treinamento das equipes, alunos e colaboradores, além da perspectiva de assinar parcerias e terceirização de determinados processos ou serviços.

Uma das grandes vantagens competitivas para as instituições de ensino que buscam a inovação na modalidade de Ensino a Distância é prever uma cadeia de suprimentos adequada e focar suas estratégias de planejamento, produção e marketing no perfil do cliente-alvo, que cresce exponencialmente no Brasil. O grande desafio para mapear a inovação é balizar os indicadores e métricas que ainda estão em processo de compilação, pois, em sua maioria, dependem das contribuições diárias e das experiências das instituições educacionais e das organizações representativas do setor e dos órgãos governamentais.

Ressalta-se, no entanto, que é fundamental a contribuição dos especialistas e de todos os atores (docentes, alunos e gestores) nesse processo de construção da EAD no País. A tarefa agora é reivindicar a implantação de uma política pública sustentável para subsidiar, com mais recursos e infraestrutura, todo o processo envolvido na modalidade a distância, oportunizando o compartilhamento igualitário do conhecimento.

\section{Referências}

ANUÁRIO Brasileiro Estatístico de Educação Aberta e a Distância - ABRAEAD. 3. ed. São Paulo: Instituto Monitor, 2007. Disponível em: <http://www.abraead.com. br/anuario/anuario2007.pdf>. Acesso em: 10 out. 2010.

AMORIM, J. A.; PIVA JUNIOR, D. Direitos autorais em EAD. In: LITTO, F. M.; FORMIGA, M. (Org.). Educação a Distância: o estado da arte. 2. ed. São Paulo: Pearson Education do Brasil, 2012. v. 2.

ARAUJO, E. M. Design instrucional de uma disciplina de pós-graduação em Engenharia de Produção: uma proposta baseada em estratégias de aprendizagem colaborativa em ambiente virtual. 2009. 217 f. Dissertação (Mestrado em Engenharia de Produção)-Escola de 
Engenharia de São Carlos, Universidade de São Paulo, São Carlos, 2009.

BELLONI, M. L. O que é Mídia e Educação. Campinas: Autores Associados, 2001.

BRASIL. Ministério da Educação e Cultura. Secretaria de Educação a Distância. Referenciais de Qualidade para Educação Superior a Distância. MEC, 2007. Disponível em: <http://portal.mec.gov.br> Acesso em: 10 out. 2010.

CYSNEIROS, P. G. Novas Tecnologias na sala de aula: melhoria do ensino ou inovação consevadora? Informática Educativa, Uniandes-LIDIE, v. 12, n. 1, p. 11-24, 1999.

D'AVILA, T.; EPSTEIN, M. J.; SHELTON, R. As regras da inovação: como gerenciar, como medir e como lucrar. Tradução de Raul Rubenich. Porto Alegre: Bookman, 2007.

IAQUINTO, K. Caminho estreito para a banda larga. Conjuntura Econômica, v. 64, n. 9, p. 27-31, set. 2010.

LEVY, S. Six factors to consider when planning online distance learning programs in higher education. Online Journal of Distance Learning Administration, v. 6, n. 1, Spring 2003.

LITTO, F. Fredric Litto fala sobre Educação a Distância. Entrevista no youtube cedida para revista Nova Escola. Disponível em: <http://www.youtube.com/ watch?v=D_5HhfcE-io\&feature $=$ related $>$. Acesso em: 03 out. 2010.

LONGO, C. Qualidade da Educação a Distância. Universia - Gestor, Tendências e Debates, 06 out. 2006. Disponível em: <http://www.universia.com.br/gestor/ materia.jsp?materia=12423>. Acesso em: 02 out. 2010.

MOORE, M., KEARSLEY, G. Distance education: a systems view. Belmont: Wadsworth Publishing Company, 1996. 290 p.
MOORE, M. G; KEARSLEY, G. Educação a Distância: uma visão integrada. São Paulo: Cengage Learning, 2008. 398 p.

PALLOFF, R.M.; PRATT, K. Construindo comunidades de aprendizagem no ciberepaço: estratégias eficientes para a sala de aula on-line. Porto Alegre: Artmed, 2002.

PRETI, O. Apoio a aprendizagem: o orientador acadêmico. In: ALMEIDA, M. E. B.; MORAN, J. M. (Ed.). Integração das tecnologias na educação: salto para o futuro. Brasília: Ministério da Educação; SEED, 2005.

SALMON, G. All things in moderation. 2000. Disponível em:<http://www.atimod.com/>. Acesso em: 26 nov. 2009.

SOUTO, M. A. M. Diagnóstico on-line do estilo cognitivo de aprendizagem do aluno em um ambiente adaptativo de ensino e aprendizagem na Web: uma abordagem empírica baseada na sua trajetória de aprendizagem. 2003. Tese (Ciência da Computação)Universidade Federal do Rio Grande do Sul, Porto Alegre, 2003. Disponível em: <http://www.lume. ufrgs.br/bitstream/handle/10183/4837/000416006. pdf?sequence=1>. Acesso em: 12 jan. 2011 .

TAROUCO, L. M. R. et al. Objetos de Aprendizagem para M-learning. In: CONGRESSO NACIONAL DE TECNOLOGIA DA INFORMAÇÃO E COMUNICAÇÃO, 2004, Florianópolis. Anais... Florianópolis, 2004. Disponível em: <http://www. cinted.ufrgs.br/CESTA/objetosdeaprendizagem_sucesu. pdf $>$. Acesso em: 2 out. 2010.

TIDD, J.; BESSANT, J.; PAVITT, K. Gestão da Inovação. Porto Alegre: Bookman, 2008.

VAN DER LINDEN, M. M. G.; AZEVEDO, W. UAB em transição: a capacitação continuada de professores e tutores para a educação colaborativa na UFBR Virtual. In: CONGRESSO INTERNACIONAL DE EDUCAÇÃO A DISTÂNCIA, 16., 2010, Foz de Iguaçu. Anais eletrônicos... Foz de Iguaçu: ABED, 2010. Disponível em: <http://www.abed.org.br/congresso2010/ cd/962010012240.pdf>. Acesso em: 30 nov. 2011. 